\title{
建筑工程深基坑支护的施工技术探讨
}

\author{
陈亮 \\ 甘肃建投土木工程建设集团有限责任公司，甘肃 兰州 730070
}

[摘要] 随着建筑行业不断发展高层建筑数量逐渐增多，在进行工程建设的过程中深基坑支护施工技术已经成为主要的施工技 术之一，深基坑支护施工质量与建筑工程整体建设质量有着直接的关系，但是在进行建筑工程深基坑施工过程中会受到地质 条件、环境因素、施工因素等方面的影响，因此在进行深基坑支护过程中应根据工程实际情况合理选择深基坑施工技术并强 化监管工作，在确保深基坑支护效果的基础上提高建筑工程整体建设质量。

[关键词]建筑工程; 深基坑支护; 施工技术

DOI：10.33142/ec.v4i2.3306 中图分类号：TU7 文献标识码：A

\section{Discussion on Construction Technology of Deep Foundation Pit Support in Construction Engineering}

CHEN Liang

Gansu construction investment Civil Engineering Construction Group Co., Ltd., Lanzhou, Gansu, 730070, China

\begin{abstract}
With the continuous development of the construction industry, the number of high-rise buildings is gradually increasing. In the process of engineering construction, the construction technology of deep foundation pit support has become one of the main construction technologies. The construction quality of deep foundation pit support has a direct relationship with the overall construction quality of the construction project, but it will be affected by geological conditions, environmental factors, environmental factors and other factors. Therefore, in the process of deep foundation pit support, we should reasonably select the deep foundation pit construction technology and strengthen the supervision according to the actual situation of the project, so as to improve the overall construction quality of the construction project on the basis of ensuring the effect of deep foundation pit support.
\end{abstract}

Keywords: construction engineering; deep foundation pit support; construction technology

\section{1 深基坑支护施工概述}

1.1 深基坑施工技术分析

在进行建筑工程建设过程中要想保证建筑结构的稳定性应合理采用深基坑支护施工技术并提高支护质量。在对以 往建筑工程深基坑施工进行调研后可以发现在施工过程中比较容易出现安全问题, 这样不仅会给施工人员安全带来影 响更无法保证建筑工程整体结构安全。因此, 在进行建筑工程深基坑支护施工过程中应对施工技术进行严格控制, 有 效避免安全事故的发生，保证支护效果。

\section{2 主要特点}

1.2. 1 深度大

城镇化建设逐渐加快, 更多的人口涌入到城市中, 这样土地资源匮乏的现象也成为比较常见的问题, 因此高层建 筑成为主要的建筑形式, 与普通建筑相比高层建筑建设规模相对较大, 这样深基坑深度也不断加深。建筑工程施工过 程中深基坑支护施工已经成为主要的施工内容, 因此对施工质量也有了更高的要求, 从而提高建筑工程整体结构的稳 定性, 所以在进行建筑工程施工时应充分了解工程施工现场具体情况并合理选择支护结构及形式, 强化支护质量控制, 提高支护工程建设质量。

\subsection{2 施工难度逐渐增加}

深基坑支护施工质量与建筑工程施工质量有着直接的关系，可以实现对建筑地下空间的有效利用，因此应对建筑 工程深基坑支护施工质量进行严格监管。但是随着建筑工规模逐渐扩大深基坑支护施工难度也随之增加, 这样就提升 了管理工作的难度, 特别是施工现场存在埋设相对较深的地下管线、地下水管线等, 会给基坑支护带来不利的影响 ${ }^{[1]}$ 。

\section{2 深基坑支护施工技术}

\section{1 土钉墙支护}

在建筑工程深基坑支护工程中土钉墙支护施工技术已经成为常用的支护方式之一，采用此种支护施工技术可以提 
高支护结构施工效果同时可以保证基坑及边坡施工质量满足要求。(1) 在进行土方开发施工前应先做好测量放线工作, 在进行此项工作时可以将施工方案及基坑口线作为依据并做好记录。（2）对土钉尺寸进行控制。在进行施工时应在选 择孔径后合理选择土钉尺寸完成钻孔施工。（3）对灌浆质量进行控制。对水灰比进行科学合理配置后确保灌浆材料质 量并对注浆摚拌顺序进行控制, 在初凝后进行二次灌浆, 并对灌浆间隔时间进行控制, 从而确保灌浆质量。

\section{2 针杆支护}

采用针杆支护施工技术进行深基坑施工时应先对针杆位置进行设定并做好勘察及支护设备选择工作, 在完成所有 准备工作后根据设计方案进行施工工作。在进行施工过程中应控制钻孔质量及深度, 将钻孔水平方向孔间距误差控制 在 $50 \mathrm{~mm}$ 以内, 垂直度孔间距误差控制在 $100 \mathrm{~mm}$ 以内。在使用针杆施工技术进行施工时应控制注浆材料质量并严格按照 标准进行施工。正式施工前应先检测浆液中是否存在杂质并采用从上之下的方式均速进行灌注, 当达到灌注标准后停 止施工。

\section{3 排桩支护或地下连续墙支护}

采用排桩支护施工技术进行深基坑支护时应根据工程实际情况合理选择支护结构, 主要包括悬臂式支护结构、拉 针式支护结构及内撑式支护结构。支护结构不同支护特点也不同, 所以在采用地下连续墙支护施工技术时可以采用内 支撑方式、逆作方式及半逆作方式等。地下连续墙施工技术在施工中优势比较明显, 主要表现在噪音不大、振动较小 且具有良好的承载力、防渗效果且刚度较强, 可以提高建筑工程施工质量。

\section{4 逆作拱墙支护}

在采用深基坑支护施工技术时会采用围护墙, 围护墙主要包括圆形、椭圆形等, 所以为了确保逆作拱墙支护结构 的稳定性及质量在施工时可以采用分层或分段施工方式。因此为了避免出现一边或多边拱起现象可以采用钢筋混凝土 结构作为支撑结构并保证水平传力。施工人员应对拱墙轴线矢跨比进行有效控制并强化结构的协调性。在施工过程中 还应对地下水位进行控制, 将其控制在基坑底面以下, 当出现高于基坑地面情况时应进行及时排水 ${ }^{[2]}$ 。

\section{3 提高深基坑支护施工技术应用效果的策略}

\section{1 做好地基结构加固}

在进行深基坑支护施工过程中要想保证基坑抗压力、强度及稳定性应做好地基结构加固工作。可以将加固剂添加 到地基土体中并进行充分搅拌, 将固化剂与土层进行深度结合后产生化学反应起到固化土层的作用。完成地基固化后 可以提高地基结构的稳定性及防水性，得到良好的支护效果，提高建筑工程施工质量。

\section{2 做好土方开挖工作}

深基坑支护施工中应严格控制土方开挖环节, 在正式开挖前应做好技术交底工作并检测所使用设备的性能, 确保 土方开发工作可以顺利开展。土方开挖工作的主要目的是取土样进行检测, 利用检测结构制定开挖方案, 并对方案的 可行性进行分析, 从而可以保证开挖作业施工效果。在进行土方开挖工程中施工人员应严格按照施工方案及流程进行 施工, 从而保证土方开挖施工可以满足工程要求。

\section{3 强化深基坑支护施工质量管理}

土方开挖后就开始进行深基坑支护施工。采用人工方式进行支护孔挖掘时可以使用钢筋混凝土护壁方式并严格监 管孔洞挖掘过程、孔洞清理、钢筋笼制作与安装及混凝土配比及灌注等环节, 在保证各环节施工质量的基础上提高基 坑支护结构的安全性。采用地下连续墙支护施工技术与抗渗墙支护施工技术时应对施工技术进行规范并做好质量验收 工作。在使用锚杆支护施工技术时应对基坑开挖高度进行控制并对针杆位置进行确定, 保证针杆机水平位置及倾斜角 度可以与针杆标高相同, 只有完成以上工作后才能进行钻孔及灌注施工同时可以对质量进行控制, 提高针杆支护的稳 固性。此外, 采用深基坑支护施工技术时应严格控制土方开挖施工及回填施工环节并对施工质量进行监管, 在了解工 程施工计划后严格控制支护施工进度及质量, 从而提高建筑工程整体结构的稳定性。

\section{4 强化防渗施工管理}

在进行深基坑支护施工时还应对施工地点地下情况进行全面了解, 避免因地下水问题给支护施工带来影响。这样 在进行深基坑支护施工过程中应强化深基坑支护防渗施工管理力度, 避免因地下水原因给深基坑支护施工带来不利的 影响。深基坑防渗施工时应先了解施工地点土层情况并制定应急方案, 对地下水位进行实时监测及排出, 从而保证深 基坑支护施工质量及水平。此外, 在进行建筑工程深基坑支护排水施工时应采用彻底防水方式, 避免因积水问题给支 
护边坡带来侵蚀，最终导致塌方问题给施工人员安全带来不利的影响。

\section{5 充分做好深基坑施工监测工作}

在进行建筑工程深基坑支护施工时还应做好基坑监测工作，基坑监测技术主要是对基坑内部渗漏情况、地质水文 情况及施工现场周边建筑情况进行严格检测, 降低外界因素给施工进度及质量所带来的影响。深基坑周边环境监测过 程中可以采用红外线检测仪、液位计、土压力计等, 采用实时监控方式确保监测效果。应将监测点布置到基坑周边区 域, 监测点深度应是基坑深度的两倍。在了解基坑周边施工环境时可以采用监测仪器得到相关的数据信息, 当发现问 题时应采用合理的方式进行处理，将问题控制在可控范围内，避免给工程带来影响。

\section{6 对施工过程进行监督管理}

建筑工程施工过程中采用深基坑支护施工技术应保证支护质量, 只有确保支护质量才能提高建筑工程整体施工质 量, 同时还应做好施工过程监督管理工作, 打造健康的施工环境。首先, 深基坑支护施工时应根据工程实际情况制定 土方开挖方案并对整个开发过程进行严格控制, 当施工过程中出现偏差时可以进行及时纠错, 在保证施工效率的基础 上提高工程施工质量及施工安全。其次, 建筑工程施工中采用深基坑支护技术可以最大限度提高工程的稳定性与安全 性, 将施工过程中的安全问题降到最低。因此在进行深基坑支护施工过程中应由专业的监管人员做好监管工作并对施 工现场人员、机械设备等进行合理的组织与安排。最后, 在进行施工现场监管过程中应强化图纸及方案管理并做好材 料质量监管，技术人员还应做好技术交底工作，在保证监管水平的基础上确保深基坑施工技术使用效果。

\section{4 结语}

随着建筑工程建设规模逐渐扩大，深基坑支护施工技术得到了广泛的应用，且在建筑工程中起到了重要的作用。 但是现阶段在应用深基坑支护施工技术时通常会因开挖施工与边坡支护要求不符、边坡施工不达标或实际施工与设计 存在差异等问题给使用效果带来影响，因此应做好深基坑支护施工管理工作，从而提高深基坑支护施工质量。同时相 关施工人员还应不断提高自身专业及操作能力, 严格按照要求进行施工, 从而到达工程施工质量要求, 更好地发挥出 深基坑支护技术在建筑工程中的作用，进而促进建筑行业发展 ${ }^{[3]}$ 。

\section{[参考文献]}

[1]赵飞.建筑工程中深基坑支护施工技术的应用研究 [J]. 建材与装饰, 2019(8): 29-30.

[2]张学峰.深基坑支护施工技术在建筑工程中的应用 [J]. 科技经济导刊, 2019, 27 (4): 99 .

[3] 李再. 深基坑支护施工技术探析 [J]. 江西建材,2020 (9) : 101-102.

作者简介: 陈亮 (1986-) 男, 甘肃省兰州市人, 汉族, 大学本科学历, 中级工程师, 研究方向建筑工程。 